THE two laboratories in Great Britain which specialise in low temperature work, namely, the Clarendon Laboratory at Oxford, under Prof. F. A. Lindemann, and the Royal Society Mond Laboratory at Cambridge, under Prof. P. Kapitza, have offered the Museum their advice and assistance, and the Committee, under the chairmanship of $\mathbf{M r}$. H. T. Tizard, includes other well-known scientific workers and representatives of industrial organisations. The exhibition is primarily intended to show the properties of substances in the following low temperature regions :--solid carbon dioxide, liquid air, liquid hydrogen and liquid helium. As the use of these gases involves the liquefaction of gases obtained from the air, there will be exhibits to illustrate how the liquefaction and separation of these gases is performed in the laboratory and on an industrial scale, while the properties and uses of the gases and liquids will also come within the scope of the exhibition. The scheme is an ambitious one and there is no doubt that, with the support which the Science Museum has already received, it should result in an exhibition of great importance and interest. Col. Mackintosh desires that it should be comprehensive and he will welcome suggestions from anyone who has not so far been approached.

\section{The Radcliffe Observatory}

WHEN in the Court of Chancery on July $2 \mathrm{Mr}$. Justice Bennett approved in principle the application of the Radcliffe Trustees for permission to remove their observatory from Oxford to a site on the high veld near Pretoria, this project, which has been the subject of discussion for several years, reached a further and important stage in its development. Although the judge has reserved his final sanction of the scheme until he is satisfied as to certain details of law and finance, it is not anticipated that these will give rise to any serious difficulty. The Radcliffe Trustees have from the outset wished for some system of close co-operation between the observatory in South Africa and the University of Oxford, and it is intended that the scheme submitted to the judge for his final sanction shall set forth plans for such co-operation in a more concrete form than has hitherto been possible. The present buildings of the Radcliffe Observatory have to be vacated in the summer of next year, when they will be taken over by the Oxford Medical School, but several years must clearly elapse before the new observatory with its 72-inch telescope will be able to commence operations on the site on the hills outside Pretoria most generously presented by the municipality of that city. When it does, it will find waiting for it a vast field of nebulæ and faint stars yet unexplored with the spectroscope.

\section{Heavy Hydrogen}

THE intensive research on the new hydrogen isotope, 'heavy hydrogen', of mass 2 , and on its oxygen compound, 'heavy water', some aspects of which have been summarised in NATURE (132, 536, 1933 ; $133,197,881,1934)$, has given rise to an extensive literature. It was to be expected, therefore, that a monograph on the subject would be written, and two such have recently appeared. In that of Prof. E. Darmois " Un Nouveau corps simple : le Deuterium ou Hydrogène Lourd", Actualités Scientifiques et Industrielles, No. 121. Paris, Hermann et Cie, 1934, pp. 24) - to consider them in alphabetical order of authors-a brief account of the course of discovery, the methods of separation, and the properties of heavy hydrogen and heavy water are reviewed, with useful numerical data. There is a short account of the utilisation of the deuterium (heavy hydrogen) nucleus in atomic disintegration, and of the compounds of deuterium apart from the oxide. The monograph of Prof. H. Mark ("Das Schwere Wasser". Leipzig and Vienna, F. Deuticke, 1934, pp. 32) covers much the same ground, but is rather fuller in some parts than that of Prof. Darmois, and the converse is also true, so that both monographs are necessary in obtaining information on the whole range of the subject up to the date when they were written. Readers of NATURE who desire information on the subject of heavy water will find these monographs very convenient and useful : it is noteworthy that many of the communications listed in the bibliographies have appeared in our columns.

\section{Chlorination of Water Supplies}

AT the recent annual meeting of the British Waterworks Association, Prof. P. S. Lelean dealt with the history and present state of the methods of chlorination of water supplies. The process was used in 1897 after an enteric outbreak at Maidstone, and its application on a large scale began in 1900 at Ostend; but the modern process, in which much smaller amounts of chlorine are used, was first put into operation in connexion with the London supplies on the initiative of the late $\mathrm{Sir}$ Alexander Houston. The method was extensively used during the War, when perfectly safe drinking water was procured in large amounts from canals and other sources of highly polluted water. In modern practice, bleaching powder has been replaced by chlorine from liquid chlorine. One part of chlorine in ten millions can. reduce Bacillus coli from 1,000 to 2 per c.c. in ten minutes. The chloramines formed by the action of chlorine on ammoniated water, however, are much more effective than chlorine alone. In the case of Thames water, an addition of 0.1 parts per million of ammonia, filtration, and addition of 0.25 parts per million of chlorine resulted in the absence of $B$. coli from 98 per cent of the samples of 100 c.c. Growth from spores is also considerably retarded. The process causes neither taste nor odour. Prof. Lelean dealt with many aspects of water chlorination in detail, and his lecture emphasised the very great service rendered to public health by the use of scientific methods by the authorities responsible for water supplies : in London, 280 million gallons per day are treated.

\section{Water Supplies in Rural Districts}

THE British Electrical Development Association, Inc., has recently issued a report on water supplies and sewage disposal in rural and small urban districts in Great Britain. The report is one which should be 